\title{
TENÍASE: UMA CAUSA RARA DE APENDICITE AGUDA
}

\author{
TAENIASIS: A RARE CAUSE OF ACUTE APPENDICITIS
}

\author{
Fábio Vieira Teixeira, TCBC-SP1; Amadeu Fernandes Filho-ACBC-SP²; \\ Antonely de Cassio Alves de Carvalho ${ }^{3}$; Talita Junqueira ${ }^{4}$; Priscila Cordeiro ${ }^{4}$
}

\section{INTRODUÇÃO}

A apendicite aguda parasitária é causa rara de inflamação do apêndice cecal. A patogênese se correlaciona, primariamente, com a obstrução do lúmen apendicular devido à hiperplasia folicular de origem infecciosa, pela obstrução mecânica por fecalito ou pela obstrução por outros agentes como sementes, corpos estranhos ou muito mais raramente por parasitas intestinais. Em nosso meio não existem dados quanto à incidência e prevalência e qual parasita seria o principal agente causador da apendicite parasitária. Baseados em estudos realizados em outros países em desenvolvimento, provavelmente, no Brasil, o Enterobius vermiculares também seja o principal parasita intestinal relacionado à apendicite ${ }^{1,2}$. Por outro lado, a apendicite aguda causada por proglotes de Taenia sp., sem dúvida, é um caso raro tanto na literatura brasileira quanto na mundial.

Frente ao exposto acima resolvemos relatar o caso clínico de um paciente com diagnóstico de apendicite aguda parasitária causada pela Taenia sp. e fizemos uma extensa revisão da literatura brasileira e mundial quanto aspectos epidemiológicos, de diagnóstico e de tratamento da doença.

\section{RELATO DE CASO}

E.D.S, 30 anos, masculino, branco, procedência remota São Paulo e procedência atual, Marília-SP. Procurou o pronto atendimento do Hospital Universitário da Faculdade de Medicina e Enfermagem da Universidade de Marília(UNIMAR) com quadro clínico sugestivo de apendicite aguda. Referia dor epigástrica tipo cólica com localização no quadrante inferior direito que teve início seis horas antes da internação. Negava febre, anorexia, vômito ou diarréia. $\mathrm{O}$ exame físico revelou um paciente em bom estado geral, afebril, acianótico, anictérico, hidratado e eupneico; os sinais vitais eram normais e existia um grau de diferença entre a temperatura axilar $\left(36^{\circ} \mathrm{C}\right)$ e a temperatura retal $\left(37^{\circ} \mathrm{C}\right)$. O exame físico do abdômen apresentava dor à palpação superficial e profunda da fossa ilíaca direita e sinal de Blumberg presente. O hemograma e o exame de urina tipo I estavam sem alteração. $\mathrm{O}$ diagnóstico foi feito baseado na história clínica e no exame físico compatível com peritonite no quadrante inferior direito. Foi indicada a laparotomia por meio da incisão de McBuney. No intra-operatório o apêndice cecal apresentava-se hiperemiado e edemaciado sem evidência de secreção ou pus intra-cavitário. Foi realizada a apendicectomia pela técnica clássica sem maiores problemas. A evolução pós operatória foi satisfatória. O paciente recebeu dieta no $1^{0}$ dia pós operatório e teve de alta 48 horas após a operação. O exame anatomopatológico do apêndice cecal mostrou "infiltrado neutrofílico na lâmina própria e na camada muscular e também revelou a presença de ovos compatíveis com Taenia sp. na camada muscular do órgão". (Figura 1) Além disso, foi encontrado um parasito dentro da luz apendicular compatível com proglote de tênia. (Figura 2) No retorno ambulatorial uma semana após a apendicectomia, o paciente estava assintomático e foi prescrito praziquantel, $10 \mathrm{mg} / \mathrm{Kg}$ em dose única oral, para tratamento da teníase.

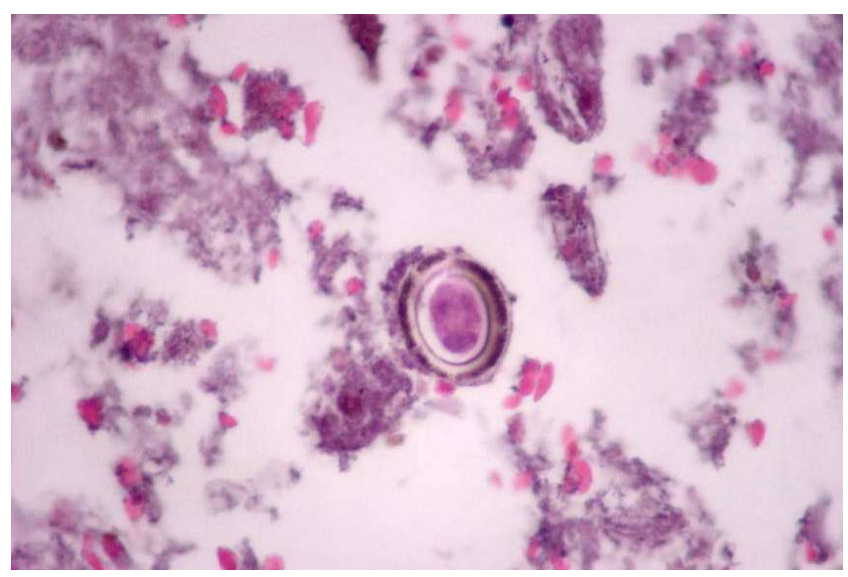

Figura 1 - Presença de ovo de Taenia sp. no interior da camada muscular do apêndice.

1. Titular do CBCD; Mestre e Doutor pela UNESP Botucatu; Fellow em Cirurgia pela Mayo Clinic Scottsdale, EUA; Docente e Coordenador da Disciplina de Clínica Cirúrgica da Faculdade de Medicina e Enfermagem (FME) da Universidade de Marília (UNIMAR).

2. Titular do CBCD; Docente e Responsável pela Enfermaria da Disciplina de Clínica Cirúrgica da FME-UNIMAR.

3. Médico Estagiário da Disciplina de Clínica Cirúrgica da FME-UNIMAR e Hospital Universitário.

4. Acadêmico do $6^{\circ}$ Ano de Medicina da FME-UNIMAR.

Recebido em 13/01/2006

Aceito para publicação em 07/03/2006

Conflito de interesses: nenhum

Fonte de financiamento: nenhuma

Trabalho realizado na Disciplina de Clínica Cirúrgica da Faculdade de Medicina e Enfermagem da Universidade de Marília - Hospital Universitário, Marília-SP 


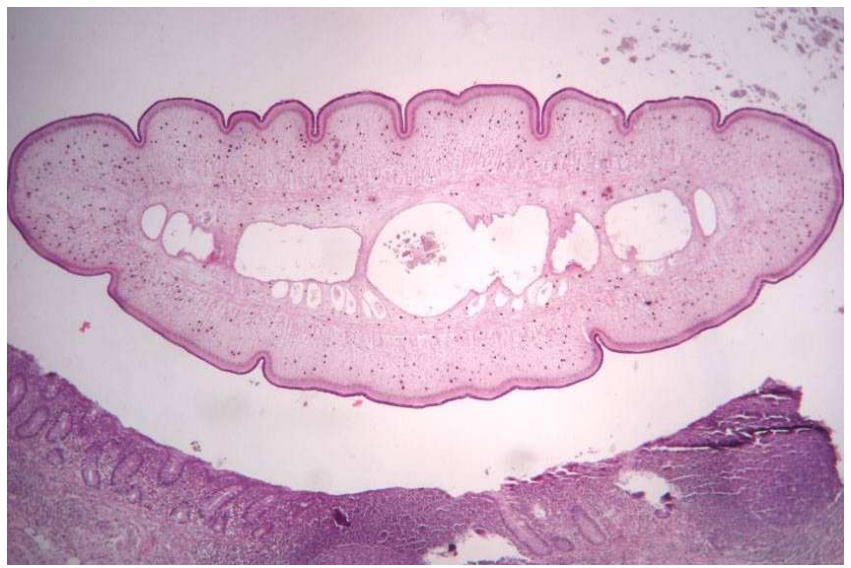

Figura 2 - Corte transversal do apêndice cecal: presença do parasita dentro da luz apendicular. (Taenia sp.)

\section{DISCUSSÃO}

Relatamos o caso de um paciente com diagnóstico de apendicite aguda, cujo exame anatomopatológico mostrou apendicite aguda devido à obstrução do apêndice cecal por proglotes de Taenia sp. Até finalizarmos este artigo, esse é o primeiro relato na literatura médica brasileira.

A teníase pode ser causada tanto pela Taenia saginata quanto pela Taenia solium. O homem é o hospedeiro definitivo da forma adulta dos parasitos intestinais sendo o bovino (T. saginata) e o suino (T. solium) hospedeiros intermediários da doença por apresentarem a forma larvária nos tecidos ${ }^{3}$. A incidência da teníase no mundo chega a 38 casos novos por milhão de habitantes ${ }^{3}$. No Brasil, a prevalência da forma adulta intestinal em estados das Regiões Sul e Sudeste é cerca de $4 \%{ }^{4}$. Acredita-se que prevalência da teníase vem aumentando no nosso país uma vez que a cisticercose tem sido diagnosticada cada vez mais principalmente nas regiões Sul e Sudeste ${ }^{4}$.

A incidência da apendicite parasitária varia de país para país. Dorfman et al. , em estudo realizado na Venezuela, encontram uma prevalência de 7,5\% de apendicite parasitária $^{2}$. Recentemente, estudo realizado na Turquia analisou o resultado de cerca de 2500 apendicectomias. A incidência da apendicite parasitária foi de $0,3 \%$. Infelizmente, existe pou- cos dados referentes à incidência da apendicite parasitária no Brasil. Acredita-se, no entanto, que seja semelhante a outros países em desenvolvimento ${ }^{1,2}$. Por outro lado, a apendicite parasitária causada por Taenia sp. é muito rara. Upton, em um estudo realizado nos Estados Unidos no início da década de 50, analisou o anatomopatológico de 80.000 apendicectomias e encontrou quatro apêndices com proglotes de tênia $(0,005 \%)^{5}$. No entanto, provavelmente, esses dados são subestimados uma vez que são referentes a um país cuja prevalência de parasitoses intestinais é sabidamente menor comparado a países em desenvolvimento como o Brasil ${ }^{4}$. Nos parece, entretanto, que não exista uma correlação direta entre a taxa de prevalência de um determinado parasita e a incidência da apendicite parasitária. No Brasil, o Ascaris lumbricoides tem prevalência de $15 \%$ entre outras parasitoses intestinais comparado a cerca de $2 \%$ de prevalência do Enterobios vermiculares ${ }^{11}$. Entretanto, o Enterobios vermiculares é apontado como o principal agente causal de apendicite parasitária ${ }^{1-3}$. Diferente do que acontece na apendicite causada pelo enterobio que invade a parede apendicular causando ulcerações e inflamação, provavelmente, a fisiopatologia da apendicite parasitária por tênia esteja relacionada à obstrução intra-luminal do apêndice vermiforme pelo parasita; no caso específico da tênia, pelos proglotes. A obstrução mecânica do lúmen apendicular por um proglote, por si só, poderia ser suficiente para causar estase, aumento da produção de muco, proliferação bacteriana, diminuição da drenagem linfática e venosa, isquemia e conseqüente inflamação do órgão.

A apendicite parasitária se manifesta por sintomas semelhantes aos observados na apendicite aguda clássica e o diagnóstico usualmente é dado pelo exame anatomopatológico. $\mathrm{O}$ tratamento é o mesmo proposto para a apendicite aguda, ou seja, apendicectomia. No entanto, uma vez que o exame anatomopatológico diagnostique a presença de parasitos, o tratamento específico para parasitose é indispensável. Quanto à teníase, duas drogas podem ser usadas no tratamento: praziquantel e albendazol. Entretanto, a droga de escolha é o praziquantel na dose $10 \mathrm{mg} / \mathrm{Kg}$ de peso em dose oral única. $\mathrm{O}$ uso do albendazol na dose de 400 mg por três a cinco dias teve resultados inferiores comparados ao uso do praziquantel ${ }^{3}$.

\footnotetext{
ABSTRACT

Acute appendicitis is the most common surgical condition of acute abdomen. Approximately 7 percent of the population will have appendicitis during their lifetime, with the peak incidence occurring between 10 through 30 years-old. Obstruction of the appendix lumen with subsequent bacterial infection initiates the pathophysiological sequence of acute appendicitis. Obstruction may have multiple causes, including fecalith, lymphoid hyperplasia (related to viral illnesses, including upper respiratory infection, mononucleosis, and gastroenteritis), foreign bodies, carcinoid tumor, and parasites. In Asia, Africa and Latin America, Enterobius vermicularis has been reported as the main parasite that causes appendix obstruction. Rarely, Taenia sp., has been pointed as a cause of parasitic appendicitis. We reported a 30 years-old patient clinically diagnosed with acute appendicitis. The appendectomy was performed through a McBurney incision. The patient's convalescence was uneventful, and he was discharged from hospital 48 hours after operation. Histological examination of the appendix showed acute appendicitis, and it was found a parasite (Taenia sp.) lying inside of the appendix lumen at a transverse section. He has received $10 \mathrm{mg} / \mathrm{Kg}$ weight of praziquantel for taeniasis treatment (Rev. Col. Bras. Cir. 2008; 35(1): 066-068).
}

Key words: Appendix; Appendicitis; Helminthes; Parasitic diseases. 


\section{REFERÊNCIA}

1. Duzgun AP, Moran M, Uzun S, Ozmen MM, Ozer VM, Seckin S, Coskun F. Unusual findings in appendectomy specimens: evaluation of 2458 cases and review of the literature. Indian J Surg. 2004;66(4):221-6.

2. Dorfman S, Cardozo J, Dorfman D, Del Villar A. The role of parasites in acute appendicitis of pediatric patients. Invest Clin. 2003;44(4):337-40.

3. Chehter L, Cabeça M. Diagnóstico e tratamento das parasitoses intestinais. In: Miszputen SJ, Schor N, editores. Gastroenterologia: guia de medicina ambulatorial e hospitalar - UNIFESP/Escola Paulista de Medicina. $1^{\text {a }}$ Ed. Barueri: Manole, 2001. p. 233-46.

4. Arruda WO, Camargo NJ, Coelho RC. Neurocysticercosis: an epidemiological survey in two small rural communities. Arq Neuropsiquiatr. 1990;48(4):419-24.
5. Upton AC. Taenial proglottides in the appendix; possible association with appendicitis. Am J Clin Pathol. 1950;20(12):1117-20.

Como citar este artigo:

Teixeira FV, Fernandes Filho A, Carvalho AC, Junqueira T, Cordeiro P. Teníase: uma causa rara de apendicite aguda. Rev Col Bras Cir. [periódico na Internet] 2008; 35(1). Disponível em URL: http:// www.scielo.br/rcbc

Endereço para correspondência:

Prof. Dr. Fábio Vieira Teixeira

Rua 21 de Abril, 385 - Bairro Maria Izabel

Marília-SP 17515-220

fabioteixeira@unimedmarilia.com.br 